\title{
Principais características anatômicas do sistema auditivo periférico de ratos e cobaias: Uma revisão literária
}

\author{
Main anatomical characteristics of the peripheral auditory system of rats and guinea pigs: \\ A literary review
}

Principales características anatómicas del sistema auditivo periférico de ratas y cobayas: Una revision literária

Diana Babini Lapa de Albuquerque Britto ${ }^{1 *}$, Carlos Fernando de Britto Costa Filho², Bruno Mendes Tenório $^{3}$, Bárbara Aparecida Flor da Silva ${ }^{4}$, Roberta França de Aguiar ${ }^{4}$, Renata Alves Calixto da Silva ${ }^{4}$, Joaci do Valle Nóbrega Júnior ${ }^{4}$, Carina Scanoni Maia ${ }^{1}$, Juliana Pinto de Medeiros ${ }^{1}$, Fernanda Chagas Angelo Mendes Tenorio'.

\section{RESUMO}

Objetivo: Descrever as principais características do sistema auditivo periférico de ratos e cobaias. Revisão Bibliográfica: Atualmente, pesquisas vêm acontecendo com o propósito de descobrir cada vez mais sobre o sistema auditivo desses animais. Para pesquisas otológicas, ratos e cobaias têm sido bastante utilizados, pela semelhança com a orelha humana. Na descrição da literatura, pode-se observar que ambos apresentam conduto auditivo externo. Apresentam semelhanças entre orelha média dos ratos e cobaias, sendo os ossículos do rato semelhante ao dos humanos, diferindo apenas em tamanho. Enquanto os humanos apresentam a mastoide do temporal, ratos e cobaias apresentam bula timpânica. Em relação à orelha interna, cócleas dos ratos e humanos são semelhantes, pois ambas possuem duas espiras e meia. Foi observado nas espiras da cóclea de cobaias, ratos e humanos, a presença de Membrana Tectória, Membrana de Raissner, Órgão de Corti e Células de Hensen, além da presença de Células Cíliadas Externas e Internas. Considerações finais: Conclui-se, desta forma, que o sistema auditivo periférico de ratos e cobaias é semelhante ao dos humanos, podendo ser utilizado em pesquisas para que haja um maior avanço científico através da aplicabilidade das avaliações técnicas in vivo que poderão ser aplicadas futuramente em seres humanos.

Palavras-chave: Anatomia, Audição, Ratos, Cobaias.

\section{ABSTRACT}

Objective: Describe the main characteristics of rats and guinea pigs' peripheral auditory system. Bibliographic Review: Nowadays, researches have been done to more about these animals' auditory system. For ontological researches, rats and guinea pigs have been commonly used, because of the human ear similarities. At the literature's description, it can be observed that both present an external ear canal. Humans present similarities among rats and guinea pigs' middle ear, like the ossicles, differing only in size. While humans present the temporal mastoid, rats and guinea pigs present tympanic bulla. With respect to the internal ear, rats and humans' cochlea are the same, because both present two and a half spirals. Was observed in the spirals and cochlea of guinea pigs', rats and humans, the presence of Tectory Membrane, Raissner Membrane, Corti Organ, and Hensen Cells, External Ciliated Cells (ECCs) and Internal Ciliated Cells (ICCs). Final Considerations: Its concluded that the rats and guinea pigs' peripheral auditory system is like humans', being able to be used in researches to a bigger scientific breakthrough through the application of technical assessments in vivo that will be able to be applied in the future in humans.

Keywords: Anatomy, Auditory, Rats, Guinea Pigs.

1 Universidade Federal de Pernambuco (UFPE), Recife - PE. *E-mail: diana.babini@gmail.com

2 Faculdade dos Guararapes (UNIFG), Jaboatão dos Guararapes - PE.

3 Universidade Federal da Paraíba (UFPB), João Pessoa - PB.

${ }^{4}$ Faculdade de Comunicação Tecnologia e Turismo de Olinda (FACOTTUR), Olinda - PE. 


\section{RESUMEN}

Objetivo: describir las principales características del sistema auditivo periférico de ratas y cobayas. Revision bibliográfica: Actualmente, pesquisas ven ocurriendo para descubrir acerca del sistema auditivos de estos animales. Para investigaciones otológicas, ratas y cobayas han sido utilizadas por su similaridad al oído humano. Se puede observar que los dos apresentam conducto auditivo exterior, tienen similitudes entre la oreja media de las ratas y cobayas, siendo los osículos similares a los humanos, diferente en lo tamaño. Mientras los humanos apresentam la mastoide temporal, ratas y cobayas apresentam bulla timpánica. En relación con el oído interno, la cóclea de las ratas y humanos son similares ya que ambas tienen dos vueltas y meia. Se observó en las vueltas de la cóclea de toda la presencia de membrana tectoria, membrana de Reissner, Órgano de Corti y células de Hensen, células ciliadas externas y células ciliadas internas. Consideraciones finales: se concluye que el sistema auditivo periférico de las ratas y cobayas es similar al de los humanos y puede ser utilizado en investigaciones para que haja un mayor avance científico mediante la aplicabilidad de las evaluaciones tecnicas in vivo puenden ser aplicadas en el futuro en los humanos.

Palabras-llave: Anatomía, Audición, Ratas, Cobayas

\section{INTRODUÇÃO}

No cenário atual, muitas pesquisas otológicas vêm sendo realizadas com o propósito de se descobrir cada vez mais sobre o sistema auditivo, tanto em relação a anatomia e fisiologia como suas patologias. Sabe-se que o uso de mostras animais tem sido cada vez mais importante para que haja um maior conhecimento da anatomia da orelha e consequentemente sua utilização adequada. Vários estudos vêm frisando a importância do uso de animais em pesquisas, para que haja um maior avanço científico através da aplicabilidade das avaliações técnicas in vivo que poderão ser aplicadas futuramente em seres humanos (FERREIRA LM, et al., 2005).

Modelos animais, principalmente os utilizados em laboratório, são alternativas viáveis para realização de estudos. Conforme relatam Schanaider A e Silva PC (2004), pesquisas no âmbito da medicina normalmente fazem uso de experimentos in vivo, como por exemplo animais de pequeno porte (camundongo, rato, hamster, cobaia ou gerbil), compreendendo quase que $90 \%$ de sua totalidade (COOPER AJ e JOHNSON CD, 1991; FAGUNDES DJ e TAHA MO, 2004).

Schanaider A e Silva PC (2004) ainda afirmam que os estudiosos da área médica realizam mais estudos inicialmente com os animais, para que cada vez mais os pacientes sejam menos submetidos aos danos e/ou aos erros, levando os profissionais assim, a ter cada vez mais excelência em suas atuações profissionais.

Para pesquisas otológicas, os ratos e as cobaias têm sido bastante utilizados, pelos seus tamanhos, facilidade de manejo, ciclo de reprodução e de vida curtos, relativo baixo custo de manutenção em biotérios e pela semelhança anatômica e patológica com a orelha média humana (HYPPOLITO MA e VASCONCELOS CAC, 2014; SANTOS PF, et al., 2005).

Albuquerque AAS, et al. (2009) descrevem que a literatura apresenta diversos estudos referentes à otologia com animais de pequeno porte. No entanto, mesmo existindo esses estudos, pode-se observar que na generalidade não há pesquisas suficientes que abordem sobre todas as possíveis características existentes na orelha externa, média e interna deles.

Em relação aos modelos animais na pesquisa audiológica, os roedores são os animais mais utilizados, muitas vezes na investigação dos mecanismos fisiopatológicos de danos auditivos e na possível reversão destes. Os autores justificam o uso de experimentos com roedores para que após as testagens corretas, seja de medicações, exames, interpretação de resultados e vantagens e desvantagens de cada técnica, os mesmos possam ser direcionados e aplicados em seres humanos (REIS A, et al., 2017).

Essa revisão de literatura traz como objetivo descrever as principais características sobre o sistema auditivo periférico dos ratos e das cobaias para que cada vez mais as pesquisas otológicas tenham parâmetro para comparar com a audição de seres humanos, tanto dentro da normalidade quando nas patologias de ouvido. 


\section{REVISÃO BIBLIOGRÁFICA}

\section{Principais características sobre a orelha externa do sistema auditivo periférico}

O sistema auditivo periférico é composto pela orelha externa (OE), orelha média (OM) e orelha interna (OI). Em relação a OE pouco se relata na literatura. Bonvicino CR, et al. (2008) relatam que as orelhas dos ratos são relativamente pequenas, meio enterradas no pelo e medem normalmente entre 20 a 23 milímetros. Fazendo uma comparação entre o conduto auditivo externo (CAE) entre ratos e cobaias, foi verificado que das cobaias é menor. Acredita-se que tanto o CAE dos ratos quanto das cobaias seja bem menos que nos humanos, que apresentam seu comprimento médio de $12,6 \mathrm{~mm}$, podendo apresentar uma variação anatômica do CAE de 12,4mm à 5,7mm (GURR $A$, et al., 2011).

\section{Principais características sobre a orelha média (OM) do sistema auditivo periférico}

Albuquerque AAS, et al. (2009) descrevem que, ao se comparar a OM dos seres humanos com a OM dos ratos e cobaias, pode-se verificar uma grande semelhança: a presença dos três ossículos (martelo, bigorna e estribo), onde nas cobaias é melhor visualizada a membrana timpânica (MT) e o cabo do martelo, ossículo existente dentro da OM e, nos ratos pode-se visualizar tanto a MT quanto a cadeia ossicular por completa martelo, bigorna e estribo. Além disso, foi observado que em relação à espessura deles, os ossículos nos ratos são mais finos e ficam quase que em sua totalidade ocultos numa região chamada epitímpano além da artéria carótida passar entre as cruras do estribo (ALBUQUERQUE AAS, 2006).

Pode-se relatar que, nos ratos, os três ossículos são individualizados. Já nas cobaias, foi encontrado uma junção que recebe a nomenclatura de incudomaleolar, a qual verifica-se que há uma fusão entre o martelo e a bigorna (KANZAKI S, et al. 2006; KANZAKI S, et al., 2009).

Nas cobaias, o estribo é maior e tem um formato triangular. Já nos ratos, os ramos anterior e posterior do estribo são mais estreitos e têm um formato arredondado (HYPPOLITO MA e VASCONCELOS CAC, 2014; JUDKINS RF e LI H, 1997). Sakamoto A, et al. (2017) ainda afirmam que o estribo de ratos difere do estribo dos seres humanos, pois nos ratos a crus anterior é curvado e a crus posterior é mais reto, enquanto nos humanos, a crus anterior é mais reta que o posterior.

Ainda em relação aos ossículos dos ratos, comparando com os padrões humanos de tamanho, os do rato são aproximadamente um quarto do tamanho e quase totalmente ocultos no epitímpano (PINALLA M, et al., 2001). Willi UB (2002) afirma que vale ressaltar em relação aos ossículos, estudos vibrométricos, onde revelam que nos seres humanos a articulação incudomaleolar é móvel e não funcionante. Sakamoto $A$, et al. (2017) descreveram que a morfologia do martelo no rato difere da do osso humano. Nos ratos, o martelo exibe uma lâmina larga e uma apófise curta apontada para a parede posterior, fina e plana, que não é aparente no ouvido dos humanos (LAVENDER D, et al., 2011). Nos humanos, o martelo encontra-se levemente apontado para a parede posterior e sua apófise curta está apontada para a parede anterior (CASTAGNO LA e LAVINKSY AC, 2006).

Por fim, vale descrever ainda que o ângulo entre o eixo anatômico (linha através do processo anterior do martelo e o curto da bigorna) e o manúbrio é muito menor nos ratos e, os dois são quase paralelos, ao contrário do que acontece nos humanos onde essa relação é quase que perpendicular (DONG W, et al, 2013; FLEISCHER G, 1978; MASON MJ, 2013).

Castagno LA e Lavinksy AC (2006) descrevem em seu estudo que o diâmetro (ântero-posterior) timpânico da membrana timpânica (MT) de ratos, apresenta entre 2,2 a 2,4mm. Quando comparada com o do ser humano, percebe-se o que chega a ser quase que um quarto do tamanho, uma vez que a membrana timpânica dos seres humanos mede entre 9,0 à 10,2mm. Ainda em relação as estruturas da OM, Judkins RF e Li H (1997) afirmam que os músculos estapédio e tensor do tímpano existentes na orelha dos ratos são bastante semelhantes a dos humanos.

Ainda em relação a OM, destaca-se a que nos ratos, a membrana timpânica é semi ocluída. Deve-se ter ciência de que esses animais, por possuírem essa característica, têm maior tendência à otite média, sendo um bom modelo para a mimetização dessa patologia (REIS A, et al. 2017). Uma outra característica da 
membrana timpânica nos ratos é que ela não veda o conduto auditivo externo em decorrência da horizontalidade da tuba auditiva, que é inerente à anatomia dos ratos (ALBUQUERQUE AAS; 2006).

A OM dos roedores está localizada no interior de um osso liso, chamado bula timpânica, que é equivalente à cavidade timpânica humana e faz parte da base do crânio (ASARCH R, et al. 1975). Quando comparadas à cobaia, as estruturas anatômicas da $\mathrm{OM}$ do rato são mais parecidas com a $\mathrm{OM}$ do ser humano. $\mathrm{A}$ única exceção é a localização mais superficial e anterorostral do nervo facial do rato (SEHITOGLU MA, et al. 1990) em relação à das cobaias e seres humanos (JUDKINS RF e LI H, 1997; PINILLA M, et al., 2001). Nos ratos, a bula timpânica envolve a cavidade da OM cheia de ar, enquanto nos humanos, as células aéreas da mastoide compostas por osso trabecular no osso temporal, abrigam os ossículos, ao invés de haver a existência de uma bula (TREUTING PM e DINTZIS SM, 2012).

Albuquerque AAS, et al. (2009) descrevem em seu estudo que tanto a bula dos ratos quanto das cobaias está localizada numa mesma região que é a parte posterior-inferior do crânio. Além disso, verificaram também que só existe união entre a porção petrosa do osso temporal com o osso timpânico deles. Por fim, Albuquerque AAS, et al. (2009) também relataram que na parte superior da bula, mais especificamente das cobaias, há um prolongamento do osso escamoso deles para que haja a formação do arco do zigomático. Por fim, os autores compararam a estrutura entre a bulas timpânicas dos ratos e cobaias e descreveram que a bula timpânica dos ratos apresenta uma junção frágil e, nas cobaias, essa junção é inteiriça e rígida.

Pinilla M, et al. (2001) ainda afirmam que para estudos envolvendo procedimentos cirúrgicos como por exemplo a estapedectomia ou a ossiculoptastia - cirurgias que envolvam substituição de ossículo(s), os ratos não são tão indicados, pois eles apresentam a sua artéria carótida passando ao longo da base da cóclea e através das cruras do estribo. Com isso, há maiores chances de hemorragia e/ou lesões cocleares, uma vez que pode existir exposição da janela oval nesses tipos de procedimentos, trazendo como consequência a morte do animal. Sakamoto A, et al. (2017) e Dong W, et al. (2013) relatam que quando o interesse dos estudos está voltado a cocleotomia sem causar danos à MT e/ou aos ossículos, em decorrência da facilidade de acesso à janela redonda e a parede lateral, os ratos são bem indicados.

\section{Principais características sobre a orelha interna $(\mathrm{OI})$ do sistema auditivo periférico}

Sabe-se que nos seres humanos, encontramos na Ol a cóclea e os canais semicirculares em sua constituição. Takechi M e Kuratani S (2010) relatam que tanto nos ratos quanto nos seres humanos existe a cápsula auditiva, onde se localiza a cóclea e canais semicirculares da OI. Hyppolito MA e Vasconcelos CAC (2014) afirmam que a cóclea dos ratos está localizada dentro da bula auditiva. Na pesquisa de Albuquerque AAS, et al. (2009) foi observado que tanto os ratos quanto as cobaias apresentam a presença da cóclea, ambas com a forma de caracol, semelhante ao do ser humano. No entanto, a cóclea das cobaias possui a presença de três espiras e meia enquanto na dos ratos, a cóclea apresentou a presença de duas espiras e meias.

Sampaio ALL e Oliveira CACP (2006) relatam que dentro da cóclea existem células sensoriais que são responsáveis pela porção sensorial do som, ou seja, habilidade de percepção do mesmo. Sampaio ALL e Oliveira CACP (2006) ainda resalvam que a mesma está localizada dentro do osso temporal, mas precisamente dentro da porção petrosa, o que a torna um órgão de difícil acesso, uma vez que o temporal é uma estrutura óssea densa.

Albuquerque AAS (2006) e Hyppolito MA e Vasconcelos CAC (2014) ressaltam ainda que pode ser observado na cóclea das cobaias as seguintes estruturas: a espira basal, a espira 2, a espira 3 e a espira apical. Enquanto nos ratos pode-se observar em sua cóclea a espira basal, a espira 2 e a espira apical, não sendo observado nos ratos a presença da espira 3. Além disso, os autores descrevem que a espira basal nos ratos apresenta uma maior rigidez e encontra-se fundida na cobertura óssea da cóclea. Dessa forma, como existe uma diferença entre o número de espiras das cobaias e dos ratos, Albuquerque AAS, et al. (2009) sugerem que pesquisas envolvendo a cóclea, mais especificamente fazendo uso de medicações que possam influenciar nela, cujo objetivo seja utilizar drogas que possam influenciar a cóclea, que se faça uso das cobaias, uma vez que há essa característica mais marcante nas cócleas desses animais. 
Albuquerque AAS (2006) e Hyppolito MA e Vasconcelos CAC (2014), descreveram que, apesar de haver diferença na quantidade de espiras entre as cócleas das cobaias e ratos, em ambas existe a presença de membrana tectória, membrana de Reissner e órgão de Corti. Porém as células de Hensen só são encontradas nas cócleas das cobaias. Hyppolito MA e Vasconcelos CAC (2014) ainda afirmam que tanto a Membrana Tectória quanto a Membrana de Reissner são semelhantes entre cobaias e ratos.

Ainda em relação à OI, Sakamoto $A$ et al (2017) descrevem que a cápsula auditiva (cápsula ótica e labirinto ósseo) de ambas as espécies estudadas, envolve a cóclea, os canais semicirculares, o sáculo e o utrículo da Ol, sendo os canais semicirculares, sáculo e utrículo, de acordo com Cogo LA, et al. (2016), os órgãos sensoriais vestibulares. De acordo com Hyppolito MA e Vasconcelos CAC (2014), esses órgãos nos ratos são constituídos tanto pelo labirinto ósseo quanto pelo membranoso, sendo este último, a parte funcional do sistema. Os autores ainda afirmam que o labirinto ósseo é preenchido pela perilinfa, e que, mais especificamente na rampa média da cóclea, encontra-se a endolinfa, porém não no sistema vestibular desses animais.

Ainda referente aos ratos, a Membrana de Reissner possui duas faces, a endolinfática e a perilinfática. Tanto nas cobaias como nos ratos a face endolinfática, é caracterizada como sendo a mais lisa, e a perilinfática é caracterizada por possuir algumas células que têm o núcleo realçado (HYPPOLITO MA e VASCONCELOS CAC, 2014).

Hyppolito MA e Vasconcelos CAC (2014) ainda afirmam que o Órgão de Corti tanto da cobaia quanto do rato apresentam células ciliadas externas (CCEs) com um padrão de distribuição ciliar em W, organizadas em três fileiras, podendo, por vezes, apresentar células supranumerárias e células ciliadas internas (CCls) organizadas em uma fileira de células.

Ainda em relação ao Órgão de Corti, destaca-se que ele é composto de uma cadeia de células em espiral repousando sobre a Membrana Basilar e há diferença entre os seres humanos e ratos. No ser humano, essas células apresentam cerca entre 28 a $40 \mathrm{~mm}$ de comprimento e, nos ratos, mede entre 15 a $20 \mathrm{~mm}$ (HYPPOLITO MA e VASCONCELOS CAC, 2014).

Albuquerque AAS, et al. (2009) e Forge A e Wright T (2002) relatam ainda que o Órgão de Corti do rato é constituído por dois tipos de CCEs e CCls organizadas regularmente, sendo quatro fileiras de CCEs e uma fileira de $\mathrm{CCls}$, e que permitem uma distribuição tonotópica das frequências sonoras. Uma outra característica interessante é que as CCEs aumentam de tamanho sistematicamente da base para o ápice sendo 20 $\mu \mathrm{m}$ na base e $65 \mathrm{~mm}$ no ápice e, o comprimento dos estereocílios também varia de $2,5 \mu \mathrm{m}$ na base para $7 \mu \mathrm{m}$ no ápice (ALBUQUERQUE AAS, et al., 2009; FORGE A e WRIGHT T, 2002; FLOCK A, et al., 1982).

Ainda em relação as CCEs dos ratos, Hyppolito MA e Vasconcelos CAC (2014) descrevem que existem, entre elas espaços, denominados espaços de nuel e, entre as CCEs e CCls, existe o túnel de Corti (FORGE A e WRIGHT T, 2002). Enquanto as CCls são piriformes, organizadas em forma de $U$, apresentam continuidade e não fazem contato com a membrana tectorial, as CCEs são cilíndricas, organizadas em forma de $\mathrm{W}$ e mantem contato com a membrana basilar.

Vale ressaltar que as CCEs e CCIs dos ratos apresentam diferenças, de acordo com o estudo de Hyppolito MA e Vasconcelos CAC (2014). Enquanto a OI dos ratos apresenta cerca de 10.000 a 14.000 células, apenas $3.500 \mathrm{CCls}$ são existentes, sendo bastante semelhante ao ser humano que apresenta aproximadamente $3.500 \mathrm{CCls}$ e $12.500 \mathrm{CCls}$ em seu sistema auditivo (BONALDI, 2015). Uma outra informação bastante relevante descrita por Hyppolito MA e Vasconcelos CAC (2014) é que as CCEs dos ratos funcionam como um amplificador coclear além de possuírem uma seletividade de frequência acurada, enquanto as $\mathrm{CCls}$ transmitem a informação sonora convertida para o Sistema Nervoso Central (SNC). Por fim, destaca-se o fato que as CCEs do rato possibilitam um aumento de $50 \mathrm{~dB}$, sendo consideradas um sistema de amplificador mecânico, as CCls não têm a capacidade de amplificar o som.

Alguns estudos afirmam o padrão de organização das CCEs dos ratos, apresentam um padrão de distribuição ciliar em W, sendo estas organizadas em três fileiras (ALBUQUERQUE AAS, et al., 2009; FORGE 
A e WRIGHT T, 2002). Hyppolito MA e Vasconcelos CAC (2014) ainda afirmam que as CCEs podem apresentar células supranumerárias nas três fileiras, enquanto as CCls organizadas em única fileira de células. Por fim, tanto nos ratos como nas cobaias, o padrão das CCEs localizadas dentro da espira basal da cóclea apresenta um padrão de boa organização.

Ainda em relação as CCEs e CCls dos ratos, é importante descrever que as CCEs possuem contrações rápidas e lentas e são banhadas por endolinfa em seu polo ciliar e perilinfa em suas porções laterais. Já as CCls possuem seletividade de frequência fina e são banhadas apenas por endolinfa em seu polo ciliar (HYPPOLITO MA e VASCONCELOS CAC, 2014).

Hudspeth AJ (1989) e Sampaio AL e Oliveira CA (2006), afirmam que há diferenças na espira 2 da cóclea dos ratos e cobaias. Enquanto a terceira fileira de CCEs dos ratos apresentam um padrão W/V que é regular, a espira apical da cóclea de ambos apresenta um desarranjo na organização do padrão W/V das CCEs e cCls.

Forge A e Tony W (2002) afirmam que a Ol é algo extremamente complexo e que o mesmo tanto fornece informações sensoriais provenientes da cóclea como o equilíbrio pela ação do sistema vestibular. Em relação ao sistema vestibular, tanto os ratos como as cobaias possuem 03 canais semicirculares, assim como os seres humanos, bem como sáculo e utrículo.

Oliveira (1989) descreve em seu trabalho que, para estudos referentes ao sistema vestibular da OI, dentre ratos e cobaias há uma predileção no uso das cobaias, uma vez que há grandes semelhanças entre o sistema vestibular deles com a dos homens.

Por fim, o sáculo na cobaia é mais estreito e fica inserido mais próximo à espira basal da cóclea, e no rato é mais largo e inserido próximo ao início da segunda espira da cóclea. As ampolas da cobaia e do rato são semelhantes na aparência, mas com o tamanho proporcional aos animais. O utrículo do rato é mais facilmente retirado que o da cobaia. (ALBUQUERQUE AAS, et al., 2009).

\section{CONSIDERAÇÕES FINAIS}

Estudos realizados com modelos animais, principalmente os de pequeno porte são alternativas bastante viáveis para a maior parte da pesquisa no ramo da saúde. Dentre as mostras animais utilizados, ratos e cobaias são os mais utilizados em busca de novas informações acerca da anatomia, fisiologia e patologia da orelha, pois além de pequenos, são facilmente manipulados, são de baixo custo, além de possuírem, de uma forma geral, uma grande semelhança de suas orelhas com a dos seres humanos. A revisão verificou que os roedores são bastante utilizados tanto em pesquisas que envolvem a fisiopatologia de alterações auditivas como também no reparo delas. Por fim, conclui-se que pesquisas neste âmbito trarão um maior avanço científico através de seus resultados que poderão ser aplicados futuramente em seres humanos.

\section{REFERÊNCIAS}

1. ALBUQUERQUE AAS. Estudo comparativo da estrutura da orelha interna de ratos e cobaias através da microscopia eletrônica de varredura [monografia]. Jaboticabal (SP): Universidade de São Paulo; 2006.

2. ALBUQUERQUE AAS, et al. Conhecimento da anatomia da orelha de cobaias e ratos e sua aplicação na pesquisa otológica básica. Rev Bras Otorrinolaringol, 2009;75(1):43-9.

3. ASARCH R, et al. Surgical anatomy of the guinea pig ear., 1975;84:250-255.

4. BONALDI LV. Estrutura e Função do Sistema Auditivo Periférico. In: BOÉCHAT, EM, et al. Tratado de Audiologia. $2^{\underline{a}}$ ed. Gen. São Paulo: Santos, 2015.

5. CASTAGNO LA, LAVINKSY AC. Cicatrização da membrana timpânica na timpanocentese com laser de argônio comparado à técnica com microlanceta: estudo experimental em ratos. Rev. Bras. Otorrinolaringol, 2006;72(6): 794799.

6. COGO LA, et al. Morphological analysis of the vestibular system of guinea pigs poisoned by organophosphate. Braz $\mathrm{J}$ Otorhinolaryngol, 2016;82(1):11-16. 
7. COOPER AJ, JOHNSON CD. Animal experimentation. Br J Surg, 1991(78):1409-1411.

8. DONG W, et al. Sound transmission along the ossicular chain in common wild-type laboratory mice. Hear Res, 2013(301):27-34.

9. FAGUNDES DJ, TAHA MO. Modelo animal de doença: critério de escolha e espécies de animais de uso corrente. Acta Cir Bras, 2004;19(1):59-65.

10. FERREIRA LM, et al. Modelos experimentais em pesquisa. Acta Cirúrgica Brasileira, 2005;20(Supl. 2 ) :28-34.

11. FORGE A, WRIGHT T. The molecular architecture of the inner ear. British Medical Bulletin, 2002(63):5-24.

12. FLEISCHER G. Evolutionary principles of the mammalian middle ear. Adv Anat Embryol Cell Biol, 1978(55):3-70.

13. FLOCK A, et al. Immunohistochemical localization of several cytoskeletal proteins in inner ear sensory and supporting cells. Hearing Research, 1982(7) :75-89.

14. GURR A, et al. Lambs' temporal bone anatomy under didactic aspects. Braz J Otorhinolaryngol, 2011;77(1):51-57.

15. HYPPOLITO MA, VASCONCELOS CAC. Macro e microanatomia e anatomofisiologia molecular do Sistema auditivo periférico do rato. In: VASCONCELOS CAC, ROLIM NETO ML. Neurociência e desenvolvimento humano: o infinito não acaba jamais. 1ª ed. Salto. São Paulo: Schoba, 2014.

16. HUDSPETH AJ. How the ear's works work. Nature, 1989(341) :397-404.

17. JUDKINS RF, LI H. Surgical anatomy of the rat middle ear. Otolaryngol Head Neck Surg, 1997;117(5) :438-47.

18. KANZAKI S, et al. Resorption of auditory ossicles and hearing loss in mice lacking osteoprotegerin. Bone, 2006(39) :414-419.

19. KANZAKI S, et al. Bisphosphonate therapy ameliorates hearing loss in mice lacking osteoprotegerin. J Bone Miner Res, 2009(24):43-49.

20. LAVENDER D, et al. Mass distribution and rotational inertia of "microtype" and "freely mobile" middle ear ossicles in rodents. Hear Res, 2011 (282) :97-107.

21. MASON MJ. Of mice, moles and guinea pigs: functional morphology of the middle ear in living mammals. Hear Res, 2013(301): :-18.

22. OLIVEIRA JAA. Audio-Vestibular toxicity of drugs. Florida: CRC Press, 1989. p.560

23. PINILLA M, et al. Ventral approach to the rat middle ear for otologic research. Otolaryngol Head Neck Surg, 2001;124(5):515-7

24. REIS A, et al. Modelos animais para avaliação auditiva: revisão de literatura. Rev. CEFAC, 2017; 19(3): $417-428$.

25. RICHARD F, et al. Surgical anatomy of the rat middle ear. Otolorynool Head Neck Surg, 1997;117: 438-447.

26. SAKAMOTO A, et al. Dissection of the Auditory Bulla in Postnatal Mice: Isolation of the Middle Ear Bones and Histological Analysis. Journal of Visualized Experiments, 2017;119:1-11

27. SAMPAIO AL, OLIVEIRA CA. Estrutura e Ultraestrutura da orelha interna dos mamíferos com ênfase na cóclea. Arquivos Internacionais de Otorrinolaringologia, São Paulo, 2016(10):228-240.

28. SANTOS PF, et al. Achados otomicrocópicos e histológicos da miringoes- clerose induzida em ratos: estudo crítico de um modelo experimental. Rev Bras Otorrinolaringol, 2005; 71(5): 668-74.

29. SCHANAIDER A, SILVA PC. Uso de animais em cirurgia experimental. Acta Cir Bras, 2004;19(4): 441-7

30. SEHITOGLU MA, et al. Surgical anatomy of the guinea pig middle car. Ear Nose Throat J, 1990; 69:9l-7.

31. TAKECHI M, KURATANI S. History of studies on mammalian middle ear evolution: a comparative morphological and developmental biology perspective. J Exp Zool B Mol Dev Evol, 2010(314) 417-433.

32. TREUTING PM, DINTZIS SM. Special senses: ear. in Comparative Anatomy and Histology: A Mouse and Human Atlas. Academic Press, 2012 (22) :419-432.

33. WILLI UB, et al. The incudo-malleolar joint and sound transmission losses. Hear Res, 2002(174) :32-44. 